REVISTA

Actualidades Investigativas en Educación

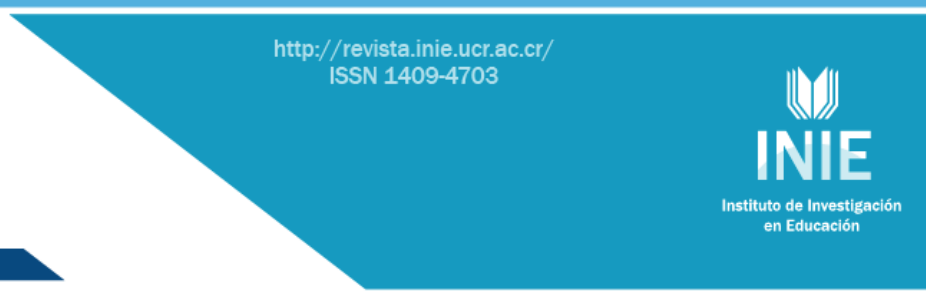

\title{
POLÍTICAS PÚBLICAS DE FINANCIAMIENTO DE LA EDUCACIÓN SUPERIOR: IMPLICACIONES PARA LA UNIVERSIDAD PÚBLICA
}

PUBLIC POLICY FINANCING FOR HIGHER EDUCATION: IMPLICATIONS FOR PUBLIC UNIVERSITIES

\section{Volumen 13, Número 3}

Setiembre - Diciembre

pp. $1-43$

Este número se publicó el 30 de setiembre de 2013

Luis Muñoz Varela

Revista indizada en REDALYC, $\underline{\text { SCIELO }}$

Revista distribuida en las bases de datos:

CATÁLOGO DE LATINDEX, IRESIE, CLASE, DIALNET, DOAJ, E-REVIST@S, SHERPA/ROMEO, QUALIS, MIAR

Revista registrada en los directorios:

ULRICH'S, REDIE, RINACE, OEI, MAESTROTECA, PREAL, CLASCO 


\title{
POLÍTICAS PÚBLICAS DE FINANCIAMIENTO DE LA EDUCACIÓN SUPERIOR: IMPLICACIONES PARA LA UNIVERSIDAD PÚBLICA \\ PUBLIC POLICY FINANCING FOR HIGHER EDUCATION: IMPLICATIONS FOR PUBLIC UNIVERSITIES
}

\begin{abstract}
Luis Muñoz Varela ${ }^{1}$
Resumen: Este ensayo se concentra en analizar las políticas públicas y los enfoques que durante los últimos años las autoridades de gobierno y algunos organismos multilaterales, en particular el Banco Mundial, han promovido y puesto en ejecución de manera general en materia de financiamiento estatal para la educación superior. Se hace referencia al modelo de autofinanciamiento instaurado en Chile en la década de 1980, así como a la última propuesta planteada en 2009 de manera conjunta por el Banco Mundial y el Gobierno de Costa Rica, en el documento Competitividad en Costa Rica. Asimismo, se menciona la negociación para la firma del quinto convenio del Fondo Especial para la Educación Superior Estatal, llevada a cabo entre 2009 y 2012, así como al préstamo pactado entre el gobierno de Costa Rica y el Banco Mundial para proporcionar un financiamiento adicional de estas universidades. Finalmente, se alude a las iniciativas y a la perspectiva bajo la cual la universidad pública ha impulsado acciones en búsqueda de diversificar las fuentes de financiación con la finalidad de flexibilizar la disposición de recursos para atender las funciones académicas e institucionales que tiene a su cargo.
\end{abstract}

Palabras clave: BANCO MUNDIAL, EDUCACIÓN SUPERIOR, POLÍTICAS PÚBLICAS, FINANCIAMIENTO ESTATAL, PRIVATIZACIÓN, RECENTRALIZACIÓN INSTITUCIONAL DEL ESTADO, FONDO ESPECIAL PARA LA EDUCACIÓN SUPERIOR ESTATAL, COSTA RICA

\begin{abstract}
This essay analyzes the public policies and approaches that the Costa Rican Government and some multilateral agencies, particularly the World Bank, have promoted and implemented for the last years in order to finance public higher education. Reference is made to the model of self-financing established in Chile in the 1980 's, as well as the latest proposal raised in 2009 jointly by the World Bank and the Costa Rican Government in the document "Competitividad en Costa Rica". Also, it is focused on the negotiation of the fifth agreement of the Special Fund for the State Higher Education (2009-2012) as well as the loan agreement between the Costa Rican Government and the World Bank to provide additional funding to public universities. Finally, this document referes to initiatives and mainstreaming under which the public University has promoted actions in pursuit of diversifying sources of financing in order to adjust the provision of resources to meet the academic and institutional functions that is responsible for.
\end{abstract}

Keywords: WORLD BANK, HIGHER EDUCATION, PUBLIC POLICY, STATE FUNDING, PRIVATIZATION, INSTITUTIONAL RECENTRALIZATION OF THE STATE, SPECIAL FUND FOR STATE HIGHER EDUCATION, COSTA RICA

\footnotetext{
${ }^{1}$ Labora en el Instituto de Investigación en Educación de la Universidad de Costa Rica. Licenciado en Filosofía de la Universidad de Costa Rica y Máster en Ciencias con Especialidad en Investigación Educativa (CINVESTAV/Instituto Politécnico Nacional de México).
}

Dirección electrónica: luis.munoz@ucr.ac.cr

Artículo recibido: 4 de febrero, 2013

Aprobado: 19 de agosto, 2013 


\section{Presentación}

Las políticas públicas de financiamiento estatal para la educación superior, a lo largo de las últimas dos décadas han enfocado su orientación hacia la transformación de los modelos anteriores, haciendo énfasis en que, en el caso de las universidades públicas, estas instituciones deben desarrollar ahora nuevas estrategias de financiación. Las restricciones de la financiación estatal para la universidad pública se empezaron a presentar de manera recurrente en Costa Rica hace varios años. La década de 1980 se sitúa como la del momento inicial, a partir de la promulgación de las políticas públicas que llegaron a ser conocidas como Planes de Ajuste Estructural (PAE).

El Estado, se señala, no cuenta ya con los recursos necesarios para atender la amplitud de necesidades que se empezaron a generar, sobre todo a partir del momento en que aumentó la demanda social por las titulaciones de educación superior.

Después de los PAE, la política pública enfocó sus énfasis de manera insistente en que la universidad pública ya no puede seguir a la espera de que el Estado le proporcione la asignación presupuestaria que ella requiere para su funcionamiento. Por esta razón, la universidad debe desarrollar sus propias estrategias y mecanismos para obtener recursos por vías no tradicionales y por medio de la identificación de otras fuentes de financiación.

En este ensayo se ofrece una aproximación analítica y reflexiva, en torno a las principales cuestiones que a lo largo de las últimas dos décadas caracterizan la definición de propuestas de política pública y de estrategias gubernamentales, en materia de financiación estatal para la educación superior pública. De manera especial, se analizan las propuestas que al respecto han promovido el Banco Mundial y la UNESCO, las dos principales entidades multilaterales cuya participación en la formulación de dichas políticas ha tenido una incidencia especial. (Dias, 2008, p. 322). Se analiza brevemente la última propuesta que fue planteada para Costa Rica en 2009 de manera conjunta por el Banco Mundial y el Gobierno de Costa Rica.

Se hace referencia también al modelo de financiación instituido en Chile en la década de 1980, basado en el esquema del autofinanciamiento y que en 2011 motivó una serie de intensas movilizaciones estudiantiles, lo mismo que importantes cuestionamientos por parte de distintas autoridades universitarias de ese país. La organización estudiantil chilena aboga por un modelo diferente, en el cual el Estado asuma la responsabilidad de proporcionar la 
financiación para la educación superior pública y en el que se elimine el actual modelo basado en las lógicas del mercado y de la privatización.

Otra dimensión de análisis que se toma en cuenta en el artículo es la referida específicamente a las iniciativas que la propia universidad pública emprendió durante los últimos años, en procura de desarrollar estrategias y mecanismos para la diversificación de las fuentes de financiación. Ésta se encuentra asociada de manera estrecha con los análisis y recomendaciones que se han discutido en el marco de foros y encuentros organizados en particular por la UNESCO (García, 2008, p. 369).

\section{Introducción}

Durante los últimos años, la demanda de formación profesional universitaria se ha expandido de manera significativa. La masificación de la educación superior que se produjo a partir de la década de 1980 colocó a la universidad pública en una nueva situación, caracterizada por la emergencia de diversas demandas: a) ampliar la capacidad instalada (infraestructura, equipos, laboratorios); b) actualizar, diversificar y ampliar la oferta académica; c) fortalecer los sistemas de estudios de posgrado; d) mejorar los servicios a la población estudiantil y los sistemas de becas; e) fortalecer la política salarial; f) desarrollar estrategias para el relevo de la planta docente; g) instituir programas de capacitación a la planta docente para su actualización pedagógica y didáctica; h) desarrollar plataformas de mediación virtual para optimizar la labor docente y favorecer mejores condiciones de estudio para la población estudiantil...

La situación en la que está inscrita la universidad pública no es sencilla y configura la necesidad de dar respuesta a otras diversas cuestiones. A criterio de J. Dias S.:

Los debates y estudios respecto a la educación superior todavía están colmados de viejas cuestiones no resueltas, como autonomía, financiamiento público, gestión democrática, relación con la sociedad, desarrollo humano sostenible, inclusión social, educación a lo largo de la vida, calidad, etc. Estos viejos temas adquieren hoy nuevas significaciones. En algunos casos, se podría decir que sufren un "secuestro semántico", en el seno de los fenómenos mundiales acogidos por la palabra "globalización". Son términos positivos, en principio, pero hay poco acuerdo respecto a sus significados y modos de ponerlos en práctica. Por ejemplo, para unos, la inclusión social es una acción de rescate de la equidad, en tanto para otros puede representar 
una actitud populista que llevaría a una pérdida de calidad. En este caso, para unos la calidad tiene valor social y democrático, es decir, está vinculada a la justicia social y a la pertinencia, mientras que para otros la calidad sólo es posible para una élite. (Dias, 2008, p. 96).

Según la Comisión Económica para América Latina y el Caribe (CEPAL), las políticas públicas impulsadas a partir de la década de 1990 para la reforma de los sistemas educativos en América Latina se concentraron en promover transformaciones en cuatro áreas: a) organización, b) financiamiento, c) calidad, d) articulación sistémica. Tales reformas se organizaron y llevaron a cabo a través de experiencias diversas. Sin embargo, según indica la CEPAL, los énfasis asumidos tendieron "a recaer en las dos primeras áreas." (CEPAL, 2000, p. 96).

Es decir, las áreas privilegiadas en las que se sitúan las acciones de la política pública vienen a ser, precisamente, aquellas en las que la autoridad gubernamental puede instrumentar mayor incidencia y control normativos para dirigir el sistema educativo y mantener sobre él una intervención política y programática a escala ampliada.

Las reformas impulsadas se vieron, por lo general, asociadas a políticas públicas basadas en directrices y recomendaciones promovidas por parte de algunos organismos multilaterales, entre ellos, de manera especial, el Banco Mundial (BM) y la UNESCO. Las políticas del BM, sobre todo, tienden a gravitar en diversos aspectos relacionados con la educación: financiación, orientación de la formación educativa, priorización de los niveles del sistema educativo que se considera deben ser atendidos de manera privilegiada: educación básica, primaria y secundaria. Se enfatiza en estos niveles, en virtud de que se aduce que en ellos se logra una mayor tasa de rentabilidad que la que, en su lugar, favorece la educación terciaria. (Grupo Especial sobre Educación Superior y Sociedad, 2000, p. 43). Por lo general, las políticas del BM pasan en buena medida a convertirse en políticas de Estado, ya que ellas se encuentran atadas a compromisos financieros contraídos por los gobiernos.

En una posición que podría calificarse casi extrema, respecto de lo anterior, en octubre de 2007, el secretario general de la Organización para la Cooperación y el Desarrollo Económico (OCDE), resaltaba que: "No hay que hacer inversiones en educación superior, si los países en desarrollo no han resuelto la cuestión de educación de base y secundaria." (Dias, 2008, p. 332). 
La Conferencia Mundial sobre la Educación Superior de 1998 (CMES 1998) presentó un planteamiento respecto de la financiación estatal para la educación superior, basado en la noción de la educación superior como un bien público. Desde esta óptica, en el planteamiento de la CMES 1998 quedó excluida la educación superior privada con fines de lucro, por considerarse que "este modelo no sería capaz de reducir la pobreza, la desigualdad, crear empleo y asegurar mayores niveles de bienestar. En tal sentido, los pronunciamientos de la CMES 1998 plantean que el Estado debe desempeñar un papel relevante en el financiamiento y en la rendición de cuentas de las instituciones. (García, 2008, p. 369).

En la CMES de 1998, la educación superior fue considerada una inversión social con impactos en la vida del individuo y con beneficios para la sociedad, principalmente en lo que se refiere a la cohesión social y al desarrollo cultural. La responsabilidad del Estado fue considerada fundamental para garantizar una financiación adecuada a la enseñanza superior. (Dias, 2008, pp. 323-324)

Las declaraciones de la CMES 1998 también calificaron como una paradoja que, mientras se abogaba por ampliar el acceso a la educación superior para cumplir con los principios de igualdad, justicia y equidad, las disposiciones estatales en materia de financiación se limitaran cada vez más. (Conferencia Mundial sobre la Educación Superior, 1998, p. 14).

Al respecto, cabe recordar aquí que, para el caso de Costa Rica, la década de 1990 representó un momento en que la universidad pública se vio afectada de manera especial por las disposiciones de una política pública de restricción presupuestaria, la cual venía estipulada por las políticas de los Programas de Ajuste Estructural (PAE). En general, los PAE repercutieron en la ocurrencia de significativas transformaciones institucionales y del modelo de desarrollo del país (Solano, 2010, p. 2). Esta situación involucró también incidencias desfavorables en materia de financiación para el sistema nacional de la educación superior pública (González, 2006, p. 197).

En los años de implantación de los PAE, la restricción de las asignaciones presupuestarias del Estado repercutió en la disminución de la capacidad adquisitiva de la comunidad académica y administrativa de la universidad pública, situación que incidió en la erosión de la planta académica. Para sobreponerse de manera mínima a esta pérdida, la 
UCR tuvo que esperar alrededor de dos décadas. Los déficits presupuestarios impactaron de manera adversa los programas de becas y otros importantes servicios de vida estudiantil, lo cual truncó sus anhelos y expectativas de llegar a convertirse en profesionales. Con los PAE "y las políticas del Fondo Monetario Internacional (FMI), se definen ciertas políticas en las que se pone en evidencia que era más importante financiar la educación básica que la universitaria" (Masís, 2012). Todo ello representó una sensible pérdida para el país y un retroceso en los niveles que en años anteriores se habían logrado alcanzar en materia de formación profesional universitaria y en la generación de condiciones para el ascenso social.

El resultado de las políticas públicas de restricción presupuestaria de los PAE representó una desmejora en la calidad de las condiciones para el desarrollo del proyecto académico de la universidad pública, así como en los alcances de la pertinencia social de dicho proyecto. A esto debe agregarse, como un hecho trascendental que marcó un punto de inflexión en la historicidad institucional de la educación superior en Costa Rica, la eclosión espectacular de la oferta privada de titulaciones de nivel universitario, que tuvo lugar de manera especial a partir de mediados de la década de 1990.

Podría decirse, en tal sentido, que la política pública de restricción estatal de financiamiento para la universidad pública, también sirvió en dicho momento para alentar y detonar en el país la proliferación de la educación universitaria privada. La política pública de restricción presupuestaria y la de privatización de la educación superior van entonces de la mano.

A partir de los PAE de la década de 1980 y hasta el presente, en Costa Rica, la universidad pública se ha visto en una situación en la que, cada vez más, las autoridades de gobierno buscan establecer políticas públicas y afianzar mecanismos para desarrollar un mayor control sobre la utilización de los presupuestos le son asignados a estas instituciones.

Se busca con ello instituir la regulación de la rendición de cuentas econométrica. Esta es una orientación de la política pública, según indica L. Baudrit (2005, p. 8), que se ha venido implantando por medio de la promulgación de nuevas leyes, así como de la reforma de otras ya existentes. Frente a tales tendencias, la UNESCO, en su lugar, ha subrayado que en la educación están asociadas otras consideraciones que deben ser tomadas en cuenta, tales como las de su valor cultural, social y cognitivo. (UNESCO, 2005, p. 96).

De igual manera, las autoridades de gobierno han insistido de manera sistemática en que las universidades públicas deben desarrollar ahora sus propias acciones de gestión, 
dirigidas a diversificar las fuentes de financiación. El Estado, se señala, ya no puede garantizar la sostenibilidad de una "superestructura estable de financiación" (García, 2008, p.370). Eso forma parte de la historia del pasado. En su lugar, el desarrollo y consolidación del mercado de la educación superior da apertura a nuevas condiciones para la universidad pública, constituyéndose en una instancia a través de la cual la política pública gubernamental encuentra un respaldo para instaurar la restricción presupuestaria para la universidad pública.

La Conferencia Regional de Educación Superior en América Latina y el Caribe de 2008 señala en su Declaración lo siguiente:

La Educación Superior como bien público social se enfrenta a corrientes que promueven su mercantilización y privatización, así como a la reducción del apoyo y financiamiento del Estado. Es fundamental que se revierta ésta tendencia y que los gobiernos de América Latina y el Caribe garanticen el financiamiento adecuado de las instituciones de Educación Superior públicas y que estas respondan con una gestión transparente. La educación no puede, de modo alguno, quedar regida por reglamentos e instituciones previstas para el comercio, ni por la lógica del mercado. El desplazamiento de lo nacional y regional hacia lo global (bien público global) tiene como consecuencia el fortalecimiento de hegemonías que existen de hecho. (CRES, 2008, p. 4)

No obstante, las orientaciones de la política pública tampoco se reducen a instaurar el desarrollo del esquema de la obtención de financiamiento por la vía de diversificar las fuentes. Se caracterizan más bien por presentar un dinamismo incesante que avanza y se profundiza, diversificando incluso su propia perspectiva.

\section{Una propuesta del Banco Mundial y el Gobierno de Costa Rica}

En fecha todavía reciente, el Banco Mundial (BM) y el Gobierno de Costa Rica publicaron un documento en el que recalcan que el sistema de educación superior universitaria de Costa Rica "requiere la búsqueda de mecanismos de financiamiento flexible y de otros incentivos para promover las mejoras en los programas y el desempeño universitario" (Banco Mundial, Gobierno de Costa Rica, 2009, p. 25). Ambas entidades señalan que, en su conjunto, el sistema de educación superior costarricense puede ser 
mejorado de manera significativa, "en términos de acceso, calidad y relevancia. No obstante, los mecanismos de financiamiento tradicionales usados en Costa Rica, combinados con autonomía universitaria, limitan la capacidad del gobierno de influir enormemente el sistema" (Banco Mundial, Gobierno de Costa Rica, 2009, p. 25).

A propósito de esta referencia que el BM y el Gobierno de Costa Rica hacen respecto de la autonomía universitaria, cabría aquí recordar lo que en 1971 decía R. Frondizi, ex rector de la Universidad de Buenos Aires (UBA):

[...] el presupuesto universitario no es una cuestión de técnica financiera y administrativa, sino que revela las grandes directivas de la universidad, sus preferencias por la investigación o la docencia, por las humanidades o la ciencia y otras importantes cuestiones que rebasan por completo el aspecto financiero. (p. 280)

En el presente, estas pasan a ser cuestiones centrales que interpelan la gestión y el quehacer académico de la universidad pública y que esta institución no puede dejar de atender, desarrollar y fortalecer. La indicación hecha en la década de 1970 por R. Frondizi se sitúa en la perspectiva de que, con base en la autonomía universitaria, la propia universidad es la que define cuál es el proyecto académico que le corresponde desarrollar, así como cuáles son los servicios que debe proporcionar a la sociedad. En tal sentido, el ex rector de la Universidad de Buenos Aires está hablando de una institución a la que se le debe reconocer toda la plena capacidad para saber, de manera fundada y apropiada, cuál es la mejor contribución que, en tanto institución de cultura superior, puede desarrollar y poner al servicio de la sociedad, a fin de cumplir con su propia misión y con sus responsabilidades institucionales. No obstante, hoy esa perspectiva ha pasado a quedar situada bajo una orientación que la pone en cuestión de manera diversa.

Está claro que las condiciones en las que le corresponde ahora a la universidad pública llevar a cabo sus actividades y funciones son muy distintas a las de hace cuatro o cinco décadas. Las realidades estructurales e institucionales de la sociedad se han modificado significativamente durante los últimos años. C. García G. señala que, entre las principales situaciones de cambio acontecidas, se pueden puntualizar las siguientes:

[...] crecimiento exponencial de la matrícula, la demanda de la educación superior por parte de actores distintos a los tradicionales (educación permanente a lo largo de toda la vida), la emergencia y crecimiento de distintas modalidades de educación superior 
privada y pública, la educación a distancia y otras muchas innovaciones, la intensificación de la internacionalización y el incremento de los procesos de globalización educativa... (García, 2008, p. 370)

La propuesta de política planteada en 2009 por el BM y el Gobierno de Costa Rica como la opción adecuada para proveer de financiamiento a la educación superior, no queda referida únicamente a la flexibilización de los mecanismos y a la búsqueda de otras fuentes de financiación, según se señala en el respectivo documento.

En el marco de la reducción de los poderes del Estado producto de las presiones internacionales, la liberalización de los mercados, las políticas y los cursos de acción de la privatización que caracterizaron la política pública del país durante las tres últimas décadas; la tendencia ha sido "promover la disminución de la inversión pública en la educación superior", a la vez demandar a las universidades públicas "un funcionamiento con criterios relativamente distintos: aumento en los costos de la matrícula, eficiencia y eficacia, racionalización y modernización." "Los gobiernos costarricenses han planteado la necesidad de que las universidades estatales generen parte de sus recursos, mediante la venta de bienes y servicios" (CONARE, 2011, p. 72).

En la propuesta del BM y el Gobierno de Costa Rica se introduce una modificación sustantiva de perspectiva, la cual se orienta a reordenar la propia estructura de organización y de distribución del financiamiento para la educación superior. Dicha modificación consiste en otorgar recursos a las universidades, por medio de un modelo de financiación que se cifra en el establecimiento y cumplimiento de "convenios de rendimiento" (o "fondos competitivos") y el cual está "basado en resultados":

El financiamiento basado en los resultados puede ejecutarse mediante convenios de rendimiento o fondos competitivos con universidades. Los convenios de rendimiento son acuerdos entre los gobiernos e instituciones que sirvan para promover innovación, calidad académica y fortalecimiento institucional. Estos requieren de indicadores de rendimiento que reflejen objetivos institucionales y de política pública. Con fondos competitivos, las instituciones $y / 0$ facultades compiten mediante procesos transparentes y claros con la presentación de proyectos que responden a ciertos criterios. En Costa Rica, por ejemplo, los fondos competitivos pueden ser útiles como 
un incentivo para promover las áreas de alta demanda en el mercado laboral (por ejemplo, ingeniería y ciencias). (Banco Mundial, Gobierno de Costa Rica, 2009, p. 25)

Es claro apreciar que una propuesta como esta modificaría de manera radical el actual modelo de financiación con que se cuenta para la educación universitaria estatal, establecido en el marco de las regulaciones del Fondo Especial para el Financiamiento de la Educación Superior Estatal (FEES). El financiamiento, además, se señala en la propuesta, pasaría a ser otorgado por la vía de la presentación de proyectos, en un concurso en el que también podrían participar las universidades privadas.

En sí, la propuesta en cuestión es de manera plena inadmisible para las universidades públicas. Lesiona estructuralmente el principio de la autonomía universitaria, al que el BM y el Gobierno de Costa Rica le atribuyen la condición de constituir una barrera que obstaculiza el establecimiento de mejores políticas gubernamentales para administrar y distribuir el financiamiento para la educación superior. Pero, además, la propuesta trasciende la matriz normativa e institucional de la autonomía universitaria, para pasar a violentar también el artículo 85 de la Constitución Política, según el cual, entre otras especificaciones estipula que el Estado:

[...] dotará de patrimonio propio a la Universidad de Costa Rica, al Instituto Tecnológico de Costa Rica, a la Universidad Nacional y a la Universidad Estatal a Distancia y les creará rentas propias, independientemente de las originadas en estas instituciones. Además, mantendrá -con las rentas actuales y con otras que sean necesarias- un fondo especial para el financiamiento de la Educación Superior Estatal. (Baudrit, 2005, p. 16)

Un análisis somero de la propuesta deja entrever cuáles podrían ser las repercusiones que ella tendría para el actual modelo de universidad pública vigente en Costa Rica. En primer lugar, lo fundamental es la transformación esencial que se buscaría instituir en materia de financiación estatal para la educación superior.

Tal cual se plantea en la propuesta, el financiamiento estaría en disposición tanto para las universidades públicas como para las privadas, otorgándose por medio de concursos de proyectos. Ello conduciría, en segundo lugar, a la instauración del principio de la competencia como eje regulador para organizar la distribución de los presupuestos. La 
evaluación y selección de los proyectos que se presentan a concurso estarían, en tercer lugar, subordinados a la política gubernamental que ostentaría la atribución de decidir cuáles son las prioridades que interesa al país atender en materia de educación superior. Aquí, según se puede ver, la matriz normativa de la autonomía universitaria quedaría en una situación de absoluta obsolescencia.

Ya en el año 2003, el BM había hecho la siguiente declaración:

El Estado debe intensificar su cooperación con el sector privado y la sociedad civil. El sector privado, por su parte, puede ofrecer los servicios educativos no sólo en la modalidad tradicional (como propietarios y operadores de los planteles privados y suministrando insumos tales como textos, materiales y equipos) sino mediante nuevas modalidades (por ejemplo administrando escuelas públicas por contrato). Las empresas también imparten capacitación y participan cada vez más en el desarrollo de estándares ocupacionales y currículos. (Banco Mundial, 2003, p. xxii)

La "flexibilización" de los mecanismos de financiación, según lo plantean el BM y el Gobierno de Costa Rica, además de significar que las universidades estatales procedan a diversificar y a crear sus propias estrategias para obtener recursos de otras fuentes, también pasa a implicar una flexibilización de la estructura del modelo por utilizar para la asignación del financiamiento por parte del Estado.

Con el nuevo modelo de financiación que se propone, por la vía de convenios de rendimiento, presentación de proyectos y basado en resultados, se quiere decir que, en general, todas las universidades (sean públicas o privadas), pasarían ahora a competir mediante la presentación de sus proyectos por los fondos estatales para la educación superior. Se indica, además, que las autoridades de gobierno serían las que, a su vez, tendrían bajo su jurisdicción definir las áreas prioritarias en las que la universidad tendría que enfocar sus iniciativas de desarrollo académico, lo mismo que la orientación y conformación de la oferta de formación profesional universitaria.

La propuesta hace énfasis en que, en la actualidad, sin embargo, la política pública de financiamiento de la educación superior se ve enfrentada a diversas dificultades, dentro de las cuales destaca de manera especial la autonomía universitaria, cuya observancia limita "la capacidad del gobierno de influir enormemente el sistema" de educación superior. 
Así las cosas, en lo anterior pueden ser apreciadas las cuestiones centrales que permiten contar con una visión de conjunto, acerca de cuáles son las tendencias en las que se cifra en la actualidad la orientación de las autoridades centrales del gobierno de Costa Rica, en materia de financiamiento estatal para la educación superior pública. Se trata de un cambio sustancial en la perspectiva y, a la vez, en el "modus operandi" de la política pública.

\section{El esquema chileno del autofinanciamiento}

Respecto de lo anterior indicado, cabe recordar lo acontecido en Chile en la década de 1980, tras la privatización de la educación superior instituida constitucionalmente por el dictador A. Pinochet. Con la rúbrica "libertad de enseñanza", se introdujo en ese momento en Chile el esquema del autofinanciamiento para la educación superior. De esa manera, Chile pasó a convertirse en América Latina en el país al que el BM aplaudió en todo momento, por considerarlo el modelo ejemplar de privatización de la educación superior en la región.

El financiamiento de la educación superior pasó a dejarse en Chile a la libre disposición que pudiera tener la empresa privada para invertir en este nivel del sistema educativo. El Estado se convirtió en "un donante pasivo de subsidios a empresas privadas cuya regulación supuestamente la ejercía el mercado a través de la libre competencia" (O'Donnell, 2011).

Desde el esquema del autofinanciamiento, las universidades públicas debieron desarrollar nuevas estrategias de gestión, para ir al mercado a buscar de qué manera colocar sus servicios académicos de formación, investigación, transferencia de tecnología y asesoría profesional.

Camila Vallejo, destacada dirigente estudiantil chilena, señala las repercusiones del esquema del autofinanciamiento y valora la situación acontecida de la siguiente manera:

El autofinanciamiento, establecido como doctrina, fue un golpe seco que dio en la esencia misma de lo que constituía el quehacer universitario hasta ese momento, condicionando y sometiendo a la Universidad a lógicas y esquemas mercantiles que le eran desconocidos. La Universidad Pública tuvo que verse obligada a competir en situaciones desfavorables en lo que se llamó "el nuevo mercado de la educación superior", se le puso precio, tuvo que venderse a sí misma para poder captar mayores recursos y continuar así con su proyecto educativo, perdió su brillo y su color, perdió su esencia transformadora y quedó botada en un rincón, ya incapaz de reconocerse a sí misma. (Vallejo, 2011) 
Valga mencionar que, desde una perspectiva un poco diferente, en Centroamérica, en el marco del VII Congreso Universitario Centroamericano del CSUCA, realizado en abril de 2011 en la Universidad Nacional Autónoma de Nicaragua/León, ${ }^{2}$ la Dirección de la Oficina de Cooperación Técnica Internacional de la Universidad Nacional (UNA) de Costa Rica presentó una ponencia con la propuesta de crear una oficina regional centroamericana para la gestión de búsqueda de recursos de cooperación internacional y de otras fuentes de financiamiento, que puedan compensar la "dificultad" que han manifestado los gobiernos de la región para proporcionar a las universidades públicas las asignaciones presupuestarias que la legislación de los diferentes países tienen estipuladas para estas instituciones.

La propuesta en cuestión surge bajo unas condiciones de contexto distintas a las que afrontaron las universidades de Chile en la década de 1990. Sin embargo, persigue una finalidad muy similar: ante la dificultad de obtener por parte del Estado los presupuestos que las universidades públicas necesitan, se plantea la necesidad de conjugar esfuerzos institucionales e interinstitucionales para definir e impulsar nuevas estrategias que favorezcan la obtención de recursos por vías no tradicionales, provenientes de otras fuentes de financiamiento.

La mención al caso de Chile es importante, además, ya que según lo indican hoy algunas dirigencias universitarias de ese país, los alcances del esquema de financiamiento por la vía de la colocación de servicios en el mercado y de la obtención de recursos por parte del sector privado, ya llegaron a su límite hace un buen tiempo. El esquema colapsó y las universidades se vieron limitadas para atender las necesidades de crecimiento que los tiempos actuales plantean a la educación superior. Por otra parte, si ya la política pública de financiamiento de la educación superior tiende a condicionar el desarrollo de las funciones y el desempeño de la universidad, eso ocurre aun a mayor escala cuando se trata de la inversión privada y, también, por parte de no pocas agencias de cooperación internacional interesadas en invertir en la educación superior universitaria.

El modelo chileno provocó una sensible segmentación del sistema de educación superior: universidades dedicadas únicamente a la enseñanza, otras pocas mantuvieron actividades de investigación y de generación de conocimiento. No obstante, ese mismo modelo también privilegió determinadas áreas de investigación, por medio de la inversión

\footnotetext{
${ }^{2}$ León, Nicaragua
} 
privada que buscaba atender y satisfacer determinados intereses específicos. La generación del conocimiento se privatiza y la universidad pierde las capacidades que había tenido anteriormente. Esto configura una situación de gran vulnerabilidad, en la medida que la universidad pasa a quedar cada vez más subordinada a directrices externas a ella.

Al respecto, cabe traer a colación lo que en 2005 señalaba la UNESCO:

[...] estamos presenciando hoy una serie de reestructuraciones cuyas consecuencias apenas se empiezan a evaluar: concentración de recursos en las universidades o departamentos con mejores resultados, o incluso separación de las funciones de investigación y enseñanza, en nombre del principio de la rentabilidad de la inversión; promoción de las disciplinas más avanzadas, especialmente en el sector clave de la ciencia y tecnología (nuevas tecnologías de la información y la comunicación, biotecnologías y nanotecnologías), en detrimento de las humanidades; y fomento de modalidades de gestión más empresariales. (UNESCO, 2005, p. 99)

El esquema chileno de autofinanciamiento se convirtió también en una némesis de hipoteca financiera para una gran proporción de la población estudiantil, imposibilitada para realizar sus estudios universitarios, a menos que se involucrase en una adversa situación de endeudamiento. Dicho sea de paso, a propósito de sistemas de crédito para financiar la realización de estudios universitarios, la ya mencionada propuesta del BM y el Gobierno de Costa Rica subraya el papel relevante que en Costa Rica juega la Comisión Nacional de Préstamos para la Educación (CONAPE). (Banco Mundial, Gobierno de Costa Rica, 2009, p.25). Dicha entidad, de conformidad con cifras que aporta el Programa Estado de la Nación, en 2009 registró un movimiento de crédito según el cual, "el 91\% de todos los créditos y el 94\% de la cartera correspondieron a estudiantes de siete universidades privadas" (Programa Estado de la Nación, 2011, p. 44).

A lo largo del año 2011, Chile fue escenario de masivas movilizaciones estudiantiles, apoyadas también por las máximas autoridades académicas de varias universidades. La finalidad que dichas movilizaciones han recalcado es la eliminación del modelo de mercado de la educación superior y, en consecuencia, para que el gobierno y el Estado retomen el compromiso y la responsabilidad de proporcionar el financiamiento a las instituciones de educación superior. 
En respuesta, el Presidente de Chile, Sebastián Piñera, insistió inicialmente en la posición de que la educación superior es un bien de mercado y de que en Chile, tras la constitucionalización de la "libertad de enseñanza" instaurada en la década de 1980 por el dictador Pinochet, ya no es posible echar marcha atrás: "Nada es gratis en esta vida, puesto que al final todo se realiza a través de los impuestos, pagados por la sociedad en su conjunto" (Gutiérrez, 2011).

Ante la reiterada presión de las movilizaciones estudiantiles, en julio de 2011 el Presidente Piñera anunció la creación de un fondo de 4.000 millones de dólares para el sistema educativo nacional, en el marco de lo que su gobierno ha denominado como un “Gran Acuerdo Nacional por la Educación”. En el anuncio presidencial no se indicó qué proporción del fondo sería destinada para la educación superior, pero sí se declaró que para este nivel del sistema educativo se buscaría:

[...] "mejorar la calidad, acceso y financiamiento de la Educación Superior, para avanzar hacia una Sociedad de Oportunidades y contribuir al sueño de todo padre y madre, cualquiera sea su condición socio-económica, de ver a sus hijos transformarse en buenos ciudadanos y buenos profesionales, sin tener que arruinarse o sobre endeudarse para pagar los aranceles o créditos, o tener que elegir cuál hijo podrá acceder a la Educación Superior y cuál no”. (Universia, 2011)

Esta propuesta del presidente Piñera no fue aceptada por las comunidades estudiantiles de Chile, en razón de que mantiene prácticamente el mismo esquema de privatización y de autofinanciamiento ya existente, con la única diferencia de que ha ofrecido mejorar las condiciones y abaratar los costos de los créditos estudiantiles.

\section{Las políticas públicas}

El Estado, señala Aguayo (2007), en la medida que es la principal fuente de financiamiento de la universidad pública, está en el derecho y la obligación de velar porque la inversión que realiza en la educación superior repercuta en "una producción de ideas, de resultados científicos y de formación razonable, intensa y de buena calidad" (p. 12).

En su lugar, puntualiza Aguayo (2007), las comunidades universitarias "tienen el derecho y el deber de hacer decentemente su trabajo, de hacerlo en ambientes decorosos y estimulantes, de sacarle el mayor fruto posible a lo que reciben (en términos de ingresos, 
recursos materiales e intangibles) y al mismo tiempo generar ideas y ofrecer una educación avanzada" (p. 12).

Sin embargo, las condiciones del presente no son tan favorables para la universidad pública:

Con presupuestos deprimidos, tiene que demostrar creciente eficiencia y dar respuestas adecuadas a un abanico de demandas llenas de implicaciones y contradicciones: producción de alta tecnología, formación de mano de obra de alto nivel, entrenamiento para atención de demandas inmediatas del mundo del trabajo, formación cualificada para ocupaciones de tipo nuevo, formación para la innovación, preservación y desarrollo de la alta cultura, recuperación de la cultura popular, educación a lo largo de la vida, formación para el emprendimiento, promoción de la ciudadanía y de la conciencia de la nacionalidad, inserción en el mundo globalizado y comprensión de las transformaciones transnacionales, capacitación de profesores de todos los niveles, formación de nuevos investigadores, ascensión social de grupos desfavorecidos, impulso a la grande industria, apoyo a pequeños productores, investigación de punta, tecnología de bajos costes y de aplicación directa en la agricultura y en los servicios, desarrollo local, nacional, regional, atención a las carencias de salud del pueblo, éxito individual y tantas otras exigencias cargadas de urgencias y, en todo caso, de difíciles respuestas. (Dias, 2008, pp. 106-107)

Durante los años recientes, pese a toda esta diversa batería de demandas, la política pública de financiamiento estatal ha ido desarrollando diversos mecanismos que se orientan a establecer un mayor condicionamiento y control sobre la universidad, sobre su quehacer académico, sus programas y proyectos. En la óptica de E. Ribeiro (2002), dicha política se puede caracterizar de la siguiente manera:

En su forma más coherente y desarrollada (...) asocia el financiamiento con indicadores de desempeño, implica una definición previa y externa a las propias universidades de las funciones sociales que ellas deben desempeñar y promueve su autonomía administrativa. (...) // Este tipo de reforma tiene carácter claramente instrumental. Se trata de crear mecanismos y organizaciones dotados de eficacia para enfrentar los problemas asociados con la expansión y la multiplicación de las funciones del sistema de educación superior. (p. 25) 
La política pública de financiamiento de la educación superior pública y de la educación superior en general, ha constituido durante los últimos años una forma de llevar a cabo procesos de reestructuración institucional y académica en estas instituciones. Al margen de las regulaciones nacionales y constitucionales existentes en los países en materia de financiación y de estatus institucional de la universidad pública, diferentes estrategias nuevas se han impulsado para la investigación, la generación de conocimientos y la transferencia de tecnología, por ejemplo. En países como Argentina, México, Chile o Brasil...

Estas tendencias ponen a las universidades públicas en una encrucijada. En un sentido, estas instituciones pueden adoptarlas y reformarse de acuerdo con los requerimientos que conlleva poner su quehacer académico en sintonía con las demandas de la empresa y del mercado. En otro sentido, pueden reconfigurar sus esquemas de organización y sus ofertas académicas, con base en una perspectiva apropiada que no les implique transformarse en una institución de educación superior diferente a la que han sido.

El BM, en su lugar, fundado en la perspectiva de la diversificación de las fuentes de financiamiento y en una mayor participación del sector privado, señala la necesidad de que las universidades mejoren la calidad de sus servicios y que desarrollen capacidades de competitividad para la captación de nuevos recursos.

Desde hace más de una década, el BM ha venido promoviendo la financiación de la educación superior a partir de crear sistemas de incentivos, los cuales cuenten con la participación de la inversión privada y con el aporte de donantes de diversa índole. Asimismo, las políticas del BM también insisten en asociar el financiamiento con su inversión en aquellas áreas a las que se califica como de importancia estratégica, especialmente las relacionadas con el desarrollo tecnológico. Para tal efecto, dicho organismo multilateral resalta el hecho de que Costa Rica haya logrado que la empresa Intel instalara una planta de alta tecnología en el país, habiendo superado a otros países candidatos como Brasil, Chile y México (Banco Mundial, 2003, p. 5).

Respecto de áreas disciplinarias, por ejemplo las de ciencias básicas y humanidades, el BM reconoce la gran probabilidad de que los inversores privados y los donantes no tengan mayor disposición ni interés por invertir en ellas. En tal sentido, se reconoce que, en un marco y bajo un esquema de financiamiento como el que se promueve establecer, estas actividades académicas se verán afectadas, "a menos que sean estimuladas activamente por líderes en educación que tengan imaginación y recursos suficientes y variados para 
comprender esa problemática" (Grupo Especial sobre Educación Superior y Sociedad, 2000, p. 13).

Desde directrices como las indicadas, para la universidad pública la negociación del financiamiento con las autoridades de gobierno tiende a volverse una cuestión cada vez más compleja. Ya no se trata únicamente de llegar a acuerdos sobre determinadas cifras presupuestarias o de acordar determinados esquemas para el otorgamiento de la financiación estatal. Más allá de esto, antes bien, en dicha negociación comienzan a emerger otras muy diversas cuestiones, que trascienden la aritmética financiera y que pasan a representar una intromisión en las decisiones internas académicas de la universidad.

La intromisión de la política pública no se restringe a la aplicación simple y mecánica de los criterios de eficiencia y eficacia en la utilización y ejecución de las asignaciones presupuestarias. A través de la axiomática de la "transparencia" basada en la rendición de cuentas econométrica, los instrumentos de la política pública también a cuestionar las propias decisiones institucionales acerca del quehacer académico de la universidad, con lo cual, obviamente, la autonomía universitaria pasa a quedar en una situación de riesgo y de vulnerabilidad. Una de las directrices impulsadas consiste en asumir "de forma implícita pero a menudo de forma muy objetiva, que la universidad pública debe constreñir sus actividades académicas a las necesarias, por lo que no debe ni tiene por qué contar con recursos suficientes y crecientes para el desempeño de sus labores” (Didriksson, 2007, p. 20).

Las restricciones de los recursos disminuyen la capacidad de la enseñanza superior de satisfacer las expectativas actuales con el nivel de calidad necesario que suele exigirse. Por ello, en muchos países la credibilidad y el prestigio de las universidades se cuestionan cada vez más. (Neave, 1998, p. 3)

En este sentido, cabe tener en cuenta la preocupación que manifiesta un reconocido dirigente de la educación superior pública, ex rector de la Universidad Nacional Autónoma de México (UNAM):

Un problema adicional es la tendencia observada, que muestra que no pocos gobiernos van disminuyendo el financiamiento de las instituciones públicas de educación, lo que las obliga a buscar recursos propios mediante la comercialización de sus servicios, el incremento en las colegiaturas o el desarrollo de otras actividades. Se trata, dicen quienes proponen este modelo, de generar un mercado competitivo para el 
desarrollo de instituciones de mayor calidad, que reduzcan o compensen simultáneamente sus costos operativos. Es decir, tratan a la educación como si fuera estrictamente un servicio comercial e intentan generar mecanismos de presión, a escala global, que promuevan alianzas interinstitucionales y proyectos en los que predomine el capital extranjero. (De la Fuente, 2007, p. 5)

En la organización de la oferta académica, la universidad pública costarricense toma como marco de referencia, aunque no necesariamente de manera exclusiva, las demandas que le formula el mercado de trabajo. Esto no podría ser de otra manera. En la medida que la universidad pública es una institución llamada a contribuir de manera sustantiva con el desarrollo nacional, el mercado de trabajo constituye una de sus instancias de referencia más importantes, aunque, valga reiterarlo, tampoco es la única.

Además, el proyecto pedagógico de la universidad pública tampoco tiene por qué quedar subrogado por el perfil de formación profesional que el mercado de trabajo demanda. En su lugar, si las disposiciones de la razón económica deben ser tomadas en cuenta, no significa que haya que enmarcar el quehacer académico de la universidad en una rendición de cuentas econométrica. Por otra parte, tampoco significa que esta institución no pueda organizar su oferta académica, de conformidad con la propia visión que ella tiene del desarrollo nacional y de las necesidades más importantes de la sociedad.

\section{Anotaciones breves sobre la última negociación del Fondo Especial para la Educación Superior Estatal (FEES)}

La negociación del Fondo Especial para la Educación Superior Estatal (FEES) ha constituido con frecuencia un escenario de complicaciones para las autoridades institucionales de las universidades públicas de Costa Rica.

EI FEES es un convenio de financiación que tiene una vigencia de 5 años y el cual quedó instituido por medio de una reforma al artículo 85 de la Constitución Política, efectuada en el año 1981. Al año 2013 han sido suscritos 5 convenios FEES, el último de los cuales representó una ardua y compleja negociación que se desarrolló a lo largo de 3 años, de 2009 a 2012.

Esta quinta negociación del FEES no solo abarcó un largo período, sino que estuvo además caracterizada por no pocas situaciones de tensión y conflicto al interior de la 
Comisión de Enlace, instancia integrada por las autoridades de las cuatro universidades públicas y los ministros de Educación, Hacienda, Planificación y de Ciencia y Tecnología. En uno de los momentos más álgidos de la negociación, las autoridades de gobierno manifestaron públicamente a la ciudadanía costarricense que el presupuesto estatal para las universidades públicas era un "cáncer" y que representaba "un enorme sacrificio en otras prioridades como seguridad ciudadana, la red de cuido e infraestructura" (Hoy en el Campus, 2010, párr. 7).

En palabras de la Dra. Yamileth González García, Rectora de la Universidad de Costa Rica en ese momento, la negociación del quinto convenio del FEES se caracterizó por la existencia de:

[...] un contexto en el que había fuerzas que querían deteriorar la imagen de la Universidad pública, al sumergir la negociación en una polémica desgastante y desgarradora, que implicó un fuerte trabajo para hacer una propuesta de financiamiento adecuada, en medio de una crisis económica. (Córdoba, 2011, párr. 5)

No es de mayor interés aquí aludir a las diversas situaciones de tensión y conflicto acontecidas en el transcurso de la última negociación del FEES. Sí interesa destacar, en cambio, que esta constituye la primera ocasión en que dicha negociación se llega a ver matizada con la presencia y participación indirecta de una representación del BM.

El gobierno de Costa Rica, en el marco de la quinta negociación del FEES, estableció negociaciones con el BM en búsqueda de pactar un préstamo por la suma de US\$200 millones, el cual tendría como finalidad servir de financiamiento complementario para atender necesidades de desarrollo en infraestructura y en otras áreas en las universidades públicas del país. Al inicio de la negociación del quinto FEES, en 2009, el CONARE había presentado al gobierno de la República una propuesta para que se les otorgara a las universidades este financiamiento complementario.

En la óptica de las autoridades de gobierno y de la representación del BM, con dicho préstamo se buscaba proveer de un financiamiento adicional a las universidades públicas, "para inversión de largo plazo en áreas prioritarias".

EI FEES, que cubre la mayor parte de los costos operativos e inversiones de las universidades, se ha distribuido normalmente entre las cuatro universidades públicas del CONARE sobre la base de tendencias históricas y acuerdos entre las cuatro 
instituciones. En ese contexto, el Convenio de Financiamiento 2010-2015 introdujo varios elementos nuevos. El financiamiento adicional será distribuido en partes iguales entre las cuatro universidades públicas del CONARE, esencialmente para responder al rezago histórico de la inversión en infraestructura, equipamiento, y formación de recurso humano, así como para consolidar un esfuerzo común en el desarrollo de ciencia y tecnología y otras áreas prioritarias. (Banco Mundial, 2012a, p. 3)

En el documento del BM titulado Documento de evaluación inicial del proyecto para un préstamo propuesto de US $\$ 200$ millones para la República de Costa Rica para un Proyecto de Mejora de la Educación Superior, se hace énfasis en que, en Costa Rica:

La mayoría de los estudiantes se gradúa en ciencias sociales y educación representando el 66 y el 72 por ciento de los diplomas otorgados por universidades públicas y privadas en 2009. Si bien algunas áreas de las ciencias sociales son económicamente importantes, las principales limitaciones se encuentran en las ciencias básicas e ingeniería, que representan menos del 20 por ciento de los graduados en universidades públicas y menos del 10 por ciento de los graduados en universidades privadas. Por otra parte, sólo el 11,6 por ciento de la oferta de programas universitarios se concentra en ciencias básicas e ingeniería. Esto se corresponde con la concentración de los mayores déficits laborales en los campos de ciencia y tecnología: ciencias básicas, ciencias informáticas, ingeniería y áreas emergentes como nanotecnología, telecomunicaciones, energía renovable y biotecnología. La cantidad de capital humano avanzado para investigación continúa siendo notoriamente baja, con una tasa de 0,78 investigadores equivalentes a tiempo completo por cada mil habitantes de la población activa, comparada con una tasa de 1,3 en Brasil y más de 2 en Chile. (Banco Mundial, 2012b, p. 2)

Según lo anterior, en el marco del Proyecto de Mejoramiento de la Educación Superior se estaría promoviendo privilegiar ciertas áreas en la oferta académica de las universidades públicas (ciencias básicas, ingeniería y tecnología), para atender y resolver los "déficits laborales" existentes en el país en dichas áreas. Desde luego, esto no tendría por qué representar ninguna inconveniencia para las universidades públicas. No tendría por qué afectar el cumplimiento de sus misiones ni la verificación de la pertinencia social de la 
educación superior pública. No obstante, sí sería necesario indicar que los equilibrios que se busca lograr y la amplitud que se desea dar a la oferta de formación profesional universitaria en las áreas indicadas, no represente una minusvaloración de otras áreas igualmente importantes, como lo son las de ciencias sociales, las humanidades y las artes.

La orientación planteada por el BM, adoptada e incluida en el Acuerdo de Mejoramiento Institucional de la educación superior pública del país, incluye también profundizar acciones y mejorar los mecanismos para asegurar la calidad de la educación superior, tareas que le quedan asignadas al Sistema Nacional de Acreditación de la Educación Superior (SINAES). A este respecto, se ha de recordar que en el documento Competitividad en Costa Rica, publicado en 2009 por el BM y el gobierno de Costa Rica, ya se subrayaba que el SINAES todavía no había logrado cumplir bien todavía con las funciones para las que fue creado.

El Sistema de Acreditación Nacional para la Enseñanza Superior (SINAES) no ha sido eficaz en la vigilancia de la calidad del nivel universitario, según su alcance nunca se amplió más allá de un nivel piloto y existen pocos incentivos para generar demanda para acreditación. (Banco Mundial, Gobierno de Costa Rica, 2009, p.23)

Sin embargo, sí sería importante recordar también que la creación del SINAES tuvo como finalidad básica contar con un espacio para llevar a cabo procesos de autoevaluación y evaluación de la educación superior con fines de mejora de la calidad. La acreditación del SINAES no se planteó como un instrumento de carácter punitivo, sino como una instancia que contribuye a la mejora de la calidad, no de índole obligatoria. Las funciones que el BM reclama al SINAES no haber cumplido, no forman parte en consecuencia de la naturaleza de las finalidades ni del quehacer para las cuales fue creada dicha entidad. Sería necesario convertir al SINAES en otra institución y definirle nuevas tareas, para que pudiera hacerse cargo de las labores de control a las que el BM aspira.

Con todo, tampoco eso garantizaría que, por ejemplo, se pudiera controlar el problema que el BM señala, el cual es la "proliferación no controlada de las universidades privadas" que, según el organismo multilateral indica, ha conducido en el país a "una situación confusa con respecto a las calificaciones de los graduados." (Banco Mundial, Gobierno de Costa Rica, 2009, p. 23). En otros países de América Latina ya han sido instituidas entidades de acreditación con carácter punitivo y bajo el control de las autoridades gubernamentales, 
como lo es el caso de El Salvador, sin que eso en definitiva haya llegado a tener una mayor incidencia para la mejora de la calidad de la educación superior, sobre todo a propósito de la oferta privada de titulaciones universitarias.

La cuestión principal que es de mayor interés resaltar aquí tiene que ver con el hecho de que en el marco del préstamo que el BM otorga al gobierno de Costa Rica para el mejoramiento de la educación superior pública, se incluya un acuerdo que busca incidir en una transformación del SINAES y que, en razón de ello, el BM haya podido a su vez incidir en la definición de una política nacional que de una u otra manera podría venir a afectar a las universidades públicas.

En relación con lo anterior, también es importante destacar aquí que, aún cuando, en principio, no existan cláusulas dentro del convenio fiduciario pactado entre el BM y el gobierno de Costa Rica que impliquen un compromiso contractual ni una vinculación directa para las universidades públicas, no obstante, la propuesta del BM sí tiende a orientarse en el sentido de definir y precisar condiciones para que estas instituciones desarrollen una gestión más enfocada a atender aspectos en los que desde hace ya varios años dicho organismo multilateral ha insistido. Entre tales aspectos, destaca el de que la universidad estreche sus vinculaciones con la empresa y con el mundo del trabajo, con la finalidad de ampliar y fortalecer las capacidades para el desarrollo de la innovación y la competitividad.

En su lugar, el CONARE, en el marco de la negociación del quinto FEES elaboró el Plan Nacional de Educación Superior Universitaria Estatal 2011/2015 (PLANES), en el que se definen cuatro pilares del FEES:

1. Ampliar la cobertura y garantizar la permanencia de los estudiantes en las instituciones universitarias estatales.

2. Garantizar la calidad y la pertinencia en la formación del Recurso Humano.

3. Continuar con las políticas de equipamiento y desarrollo de la infraestructura que fortalezcan la innovación y el desarrollo científico y tecnológico.

4. Impulsar el desarrollo de las diferentes regiones del país, enfatizando en la población más desfavorecida socialmente. (CONARE, 2011).

En estos cuatro pilares se basaron las autoridades institucionales de las universidades públicas como marco de referencia para desarrollar su proceso de negociación del quinto 
FEES. Y fue este el enfoque de educación superior pública que, en definitiva, prevaleció en el marco de dicha negociación.

No obstante, sí es de interés indicar aquí que, aún cuando el Proyecto de Mejoramiento de la Educación Superior (PMES) pueda ser considerado como una iniciativa inscrita en las condiciones estrictamente para la captación de los recursos del préstamo por parte de las universidades públicas, lo cierto es que alcanza a señalar otras directrices por las cuales el BM ha abogado en sus planteamientos durante los últimos años. Así, por ejemplo, en el componente primero del PMES, “Acuerdos de Mejora Institucional”, se señala lo siguiente:

El objetivo de este Componente sería: (i) ayudar a que las universidades estatales incrementen el acceso por medio de invertir en infraestructura para la enseñanza, el aprendizaje y la investigación; (ii) incrementar la calidad de la educación superior por medio de, entre otras cosas, la mejora de las cualificaciones del cuerpo docente y el fomento de la evaluación y la acreditación; (iii) aumentar la relevancia de la educación superior por la focalización de recursos en disciplinas prioritarias para el desarrollo del país; y (iv) fortalecer la capacidad de gestión y de rendición de cuentas de las universidades estatales, fortaleciendo una cultura de: (a) planificación estratégica de largo plazo, incluyendo la formulación de una misión, visión y estrategia institucional; y (b) medición, definición de metas, rendición de cuentas, monitoreo y evaluación, que pueda llevar a mayores innovaciones de financiamiento basadas en desempeño. (Banco Mundial, 2012a, p. 6)

Habría que recordar que precisamente en el documento Competitividad en Costa Rica (Banco Mundial, Gobierno de Costa Rica, 2009), se hacía hincapié también en la propuesta de instituir modalidades de financiación de la educación superior pública por medio de concursos de proyectos y con base en la verificación de resultados.

Entre los años 2009 y 2012, en el marco de una negociación ardua del quinto FEES, las universidades públicas lograron llegar a un acuerdo con el gobierno de la República, el cual mantiene vigentes los principios fundamentales de la educación superior pública. En su caso, la ejecución del Proyecto de Mejoramiento de la Educación Superior, financiado con recursos del préstamo del $\mathrm{BM}$, tendrá como figura jerárquica superior una Unidad de Coordinación, la cual estará bajo el control del CONARE. 


\section{Recentralización de la institucionalidad del Estado costarricense}

En la UCR, L. Baudrit llama la atención acerca de lo que él califica como un proceso en curso de "recentralización" de la institucionalidad del Estado costarricense (p. 8). Se trata de políticas públicas y de cursos de acción que, en particular, otorgan nuevas competencias y poderes a la Contraloría General de la República (2005, p. 4). En dicho marco, una estrategia ha consistido en instituirle a la universidad pública regulaciones en materia de ejecución presupuestaria y de rendición de cuentas similares a las que se aplican a otras instituciones, sin tomar en cuenta o minimizando los alcances del principio de la autonomía universitaria.

Esto configura una situación en la que se pone en cuestión la naturaleza y esencia institucional mismas de la universidad pública, incluso en su condición de institución de cultura superior, tal como se estipula en el artículo 84 de la Constitución Política. Las disposiciones interpuestas a la UCR por la Contraloría General de la República tienen implicaciones que afectan a la institución en todas las dimensiones de su quehacer académico y de la gestión institucional.

El financiamiento estatal pasa a configurar una política y a constituirse en un instrumento dirigido a incidir en la transformación de la universidad pública, a la cual, entre otras especificaciones, se le recomienda adoptar una nueva orientación pedagógica, aquella que de manera eficaz y eficiente conlleve la reducción de los costos de la formación. El proyecto académico de la universidad, se ha dicho, es económicamente oneroso y presenta una baja tasa de rentabilidad.

En tal sentido, se arguye, los costos de formar a una persona en las entidades privadas de la educación superior son comparativamente bastante menores. La universidad pública, por consiguiente, estaría incurriendo en un despilfarro de recursos y habría pasado a constituir una carga para el Estado y para el bolsillo de toda la ciudadanía que, en último término, mediante los impuestos que paga, es la que asume lo que se califica como un proyecto académico oneroso. Al respecto, la representante de una entidad privada de educación superior de Costa Rica pone en cuestión el cumplimiento de la transparencia por parte de la universidad pública en materia de costos por estudiante, razón por la cual expresa además su oposición al incremento de los presupuestos que el Estado otorga a estas instituciones por medio del FEES: 
¿Por qué más bien no publican las universidades que son costeadas, con el sacrificio de todos los costarricenses, el costo real por estudiante, por carrera? ¿Por qué no indican cuál es el estatus socioeconómico de los estudiantes que cursan las diferentes carreras y que están becados? (Castro, 2010, párr. 9)

Obviamente, los intereses del mercado de las titulaciones de educación superior están cifrados en la libre competencia; aun cuando, de manera curiosa, el argumento de la libre competencia sea utilizado en no pocas ocasiones por algunas entidades privadas como estrategia para reclamar que el Estado también debe proporcionarles financiamiento a ellas.

A tal efecto, se señala por parte de representantes de las entidades privadas de educación superior:

Las universidades privadas tienen el derecho constitucional de concursar por fondos estatales para financiar la investigación en sus instituciones, y de recibirlos. Esto no las convierte en entidades públicas, como tampoco a las públicas las convierte en privadas el que cobren matrículas o que vendan servicios a terceros. (Castro, 2009, párr. 1).

Pareciera, en consecuencia, que el mecanismo de créditos para realizar estudios de nivel superior -que en Costa Rica representa la CONAPE- no es suficiente.

En el marco de todos estos cuestionamientos, la universidad pública afronta además el desafío de que, en el presente, no solo es la universidad privada la que desarrolla la oferta de titulaciones, sino que la formación también ha pasado a ser asunto de las propias empresas, así como de las universidades corporativas que han empezado a operar a escala transnacional y cuya oferta de formación se lleva a cabo en línea y a costos extraordinariamente bajos. El desafío aquí planteado consiste en la manera en que la universidad pública puede asegurar a la sociedad la pertinencia social de la educación superior.

A tal efecto, el BM lanza una clara y abierta ofensiva: "Este crecimiento del sector privado refleja no sólo la demanda cada vez mayor de una oferta educativa de mejor calidad, sino también la insatisfacción con el sistema tradicional de formación y capacitación" (Banco Mundial, 2003, p. xix).

Al propio tiempo, una perspectiva como la que promueve la OCDE, en la que se indica que los países en desarrollo, para atender las correspondientes necesidades que pudieran 
existir en materia de formación a escala de la educación superior, no deberían invertir más en esta última si antes no han resuelto el fortalecimiento de la educación primaria y secundaria, para atender las correspondientes necesidades que pudieran existir en materia de formación a escala de la educación superior, se propone lo siguiente:

Los países en desarrollo deberían aprovechar las ofertas sobre educación superior ofrecidas por proveedores extranjeros ya que las directrices en cuanto a calidad en educación transfronteriza propuestas por la OCDE facilitan la identificación de proveedores de alta calidad. (Dias, 2008, p. 333)

No obstante, M. A. Dias, con quien no se podría estar sino de acuerdo, se contrapone a las anteriores afirmaciones señalando lo siguiente:

En la medida en que el comercio cambie el criterio dominante de la definición de políticas educativas, la educación ya no será para todos. Será para aquellos que puedan pagarla. No se respetará la cultura local ni se atenderá de forma prioritaria las necesidades nacionales y regionales. No habrá restricciones a paquetes cerrados, que no tienen en consideración las características culturales locales. (Dias, 2008, p.341)

A la universidad pública se le ha exigido ya desde hace algunos años que sea eficiente, eficaz y transparente en la rendición de cuentas. En tal sentido, la definición que se da a los conceptos de eficiencia y eficacia se orienta a señalar que esta institución tendría que asumir hoy de manera irrestricta la condición de ser ella también una institución competitiva. En ello está incluida la rendición de cuentas, que desde la óptica de las instancias contraloras del Estado debe ser de índole contable, gerencial, econométrica. De lo contrario, automáticamente la universidad pública se pondría en una posición inconsecuente e irresponsable, ya que estaría desatendiendo cumplir con el importante precepto de la pertinencia social de la educación superior.

La eficiencia y la eficacia en la utilización de los recursos involucran, en consecuencia, la reorganización en su conjunto de todas las actividades académicas de la universidad. Los requerimientos de la rendición de cuentas econométrica introducen nuevos parámetros para la gestión y distribución de los recursos. Por eso, en caso de que la universidad pública quisiera mantener su propio proyecto académico en vigencia, tendría que desarrollar 
acciones e impulsar iniciativas para la diversificación de las fuentes de financiación. Con ello, no obstante, la universidad quedaría en una situación complicada, en la medida que, por lo general, las fuentes alternativas de financiamiento no están dispuestas a invertir en educación superior, salvo bajo determinadas finalidades y condiciones.

Lo anterior involucra, de manera automática, la demanda de que la universidad pública, en un contexto en el que han aparecido múltiples nuevos proveedores de titulaciones universitarias, desarrolle acciones para "racionalizar" los planes de estudio y las mallas curriculares de las carreras. Se indica que el proyecto de formación de estas instituciones es oneroso y, por tal razón, se vuelve también poco competitivo. En la base discursiva de la figura de la rendición de cuentas econométrica se encuentra el señalamiento de que a la onerosidad económica que implica la inversión para formar a una persona en la universidad pública, se agrega además la onerosidad del tiempo que se tarda para que esa persona concluya sus estudios y alcance a obtener la titulación. Desde esta matriz discursiva, la formación integral que la universidad pública proporciona habría pasado entonces a carecer de toda pertinencia social y pedagógica.

A la universidad pública se le demanda modificar su perspectiva pedagógica y curricular de la formación, además de incorporar cambios significativos en la organización disciplinaria de la oferta académica. Según lo han planteado las autoridades de gobierno y organismos multilaterales como el BM, el Estado no puede continuar invirtiendo en la formación de personas que después de concluidos sus estudios pasan a quedar en una condición de "cesantes ilustrados", como ocurre, por ejemplo, con las carreras de las áreas de humanidades y las artes. (Grupo Especial sobre Educación Superior y Sociedad, 2000, p.26). Antes bien, la organización disciplinaria de la oferta académica que ahora se requiere debe concentrarse en las carreras de las áreas definidas por la política pública como prioritarias y estratégicas para el mercado de trabajo: preferentemente, las áreas técnicas y tecnológicas; las áreas de la "economía global del conocimiento", tal como lo indica el enfoque planteado por el BM (Banco Mundial, 2003, p. xvii).

La demanda de la política pública por diversificar las fuentes de financiación está asociada también a la presión que ahora ejerce el mercado de trabajo, en el sentido de contar en la oferta laboral con una cantidad más amplia de personas que posean formación técnica especializada. Dicha presión del mercado de trabajo ha tenido en la sociedad la 
repercusión de que se genere una demanda de carreras cortas y técnicas cada vez más creciente.

Esta situación conduce a que ya no sea suficiente con el financiamiento que el Estado puede aportar. Se le plantea a la universidad, entonces, que no solo sea eficiente y eficaz en la utilización de sus recursos y en la administración de los planes de estudio, sino que, además, responda a la exigencia de desarrollar una mayor capacidad de absorción de matrícula, para lo cual debe desarrollar a la vez la capacidad de obtener recursos mediante la diversificación de las fuentes de financiamiento.

En coincidencia con la situación indicada por L. Baudrit en su análisis ya citado acerca de lo que en la actualidad acontece en Costa Rica, F. López (2008) subraya lo siguiente:

La tendencia actual es la de ampliar la autonomía de procedimientos (de medios, procesos, gestión) y controlar los resultados y productos (regulación centralizada, evaluación, acreditación, accountability). Se limita la libertad de los docentes y estudiantes en la concepción y ejecución de planes de estudio. Se trata, entonces, de "autonomía controlada". (p. 51)

A tal efecto, L. Baudrit (2005) hace énfasis en precisar cuál es la naturaleza institucional de la Universidad de Costa Rica y, por extensión, de la universidad pública en general. Su análisis se basa en el artículo 84 de la Constitución Política de Costa Rica, que a la letra establece lo siguiente:

La Universidad de Costa Rica es una institución de cultura superior que goza de independencia para el desempeño de sus funciones, y de plena capacidad jurídica para adquirir derechos y contraer obligaciones, así como para darse su organización y gobierno propios. Las demás instituciones de educación superior universitaria del Estado tendrán la misma independencia funcional e igual capacidad jurídica que la Universidad de Costa Rica. (...) El Estado las dotará de patrimonio propio y colaborará en su financiación. (p. 11)

El tal sentido, el citado especialista subraya lo siguiente:

Se trata de una norma de la Constitución Política que otorga, no ya autonomía, sino independencia a la Universidad de Costa Rica en términos muy amplios, tales que es difícil que exista otro país en el mundo que hubiese consagrado la autonomía 
universitaria a nivel constitucional, sin subordinarla a regulaciones legales. // En otras naciones, la autonomía universitaria también es reconocida constitucionalmente, pero sus alcances quedan sujetos a lo que disponga la ley ordinaria. Esto permite que el Congreso o el Órgano Legislativo pueda limitar o condicionar los alcances de este concepto fundamental. Tales restricciones, impuestas por la legislación ordinaria, no son posibles en Costa Rica. (Baudrit, 2005, p. 11)

Por consiguiente, en Costa Rica:

La institución universitaria (pública, estatal) está regulada tanto por las normas de la Constitución Política, de las que depende directamente -sin intermediación de disposiciones del Poder Legislativo ni del Poder Ejecutivo-, como por las propias disposiciones universitarias. No existe subordinación de la Universidad ni a la Asamblea Legislativa ni al Poder Ejecutivo. (Baudrit, 2009, p. 8)

A su vez, a escala del sistema institucional del país, cabe destacar qué no es la Universidad de Costa Rica. Dice L. Baudrit (2005): la Universidad de Costa Rica no es una institución autónoma, ni descentralizada, "ni una institución estatal cualquiera" (p. 5).

Si bien la Universidad de Costa Rica es una institución estatal, o del Estado (...), también es cierto que constituye una persona jurídica, con plena capacidad, distinta del Estado, que no se confunde con él y que, respecto de él, goza de independencia funcional. No se encuentra subordinada al Estado, como sí lo están los órganos que integran el sector centralizado, y en alguna medida también los entes u órganos comprendidos dentro del denominado sector descentralizado. (Baudrit, 2005, p. 9)

Estas son las especificaciones constitucionales que definen la naturaleza institucional de la Universidad de Costa Rica y, por extensión, de la universidad pública en Costa Rica. En la actualidad, tal como ya ha sido señalado, la naturaleza institucional de la universidad pública en el país se estaría viendo afectada, a raíz del intervencionismo cada vez mayor que han empezado a desarrollar las autoridades de gobierno, a través del proceso de "recentralización" institucional y de la nueva política pública que otorga a la Contraloría General de la República competencias y poderes que van más allá de las atribuciones 
originales para las que constitucionalmente fue creada, en su calidad de órgano auxiliar de la Asamblea Legislativa.

\section{Puntualización sobre la rendición de cuentas}

La política pública de los últimos años se ha hecho cargo de estipular la "transparencia" y la "rendición de cuentas", como una responsabilidad de la universidad y como una obligación que esta institución debe cumplir. Sin embargo, dichas estipulaciones vienen a ser ahora un poco extrañas para la universidad.

De parte de representantes de las entidades privadas de educación superior, la rendición de cuentas de la universidad pública también ha sido cuestionada:

Rendir cuentas públicas no significa enviar los presupuestos a la Contraloría General de la República, por el contrario, este debería significar que cualquier ciudadano o investigador debería tener acceso a estos informes en un sitio web, donde podamos ubicar las últimas actualizaciones de los planes de estudio y el cumplimiento de los contenidos de los programas, cantidad de alumnos matriculados, las plazas y periodos de graduación y cuál es su composición sociodemográfica estudiantil, y el costo total de educar a cada estudiante, ya sea becado no. De esta manera, tendremos una clara rendición de cuentas. (Castro, 2012, párr. 9)

La rendición de cuentas nunca ha sido una cuestión a la que la universidad le haya opuesto objeción alguna, desde ninguna circunstancia. La figura de la rendición de cuentas no constituye ninguna novedad, en el marco de la organización de las actividades académicas y de las tareas de gestión de la universidad.

Ya en 1935, L. Galdames, a propósito del proyecto para la creación de la UCR, señalaba que la rendición de cuentas es una responsabilidad especial a la que la universidad siempre debe estar atenta a prestar la mayor atención. La universidad es una institución financiada con recursos del Estado y, por consiguiente, la rendición de cuentas le es consustancial a su quehacer y responsabilidades.

No obstante, en tanto institución de cultura superior, las funciones que la universidad pública desarrolla no pueden ser, en ningún caso, evaluadas ni fiscalizadas con base en indicadores de rendición de cuentas similares a los que se utilizan para otras instituciones, en la medida en que de esa manera se llegaría a distorsionar la naturaleza institucional de la 
universidad y en que la autoridad gubernamental podría utilizar los instrumentos de la financiación estatal para condicionarla e intervenir en la toma de decisiones que le es propia. En este aspecto, decía L. Galdames (1935, p. 84), es donde reside justamente el mayor peligro para las labores y para la estabilidad de la institución; es en este aspecto donde la universidad puede llegar a quedar colocada en una situación de "permanente zozobra".

Si sus rumbos no agradaran a la autoridad política, no sería raro que el enojo de ésta se manifestase con la restricción de los recursos; y en tal caso, la autonomía entera quedaría en el papel. Por eso se tiende a crear para la Universidad un fondo propio, que a la larga exonere al gobierno de la obligación de consultarle sumas globales en los presupuestos de cada año. Mientras tanto, cabe confiar en que los hombres que ejerzan el poder político mantengan la conciencia de sus deberes para con la cultura y la lealtad para el cumplimiento de la ley. (Galdames, 1935, p. 84)

El fondo propio al que ya en 1935 se refería L. Galdames, aunque no exactamente en los términos en que él lo entendía, pasó posteriormente a quedar consignado en el artículo 85 de la Constitución Política y, en la actualidad, se encuentra instituido en Costa Rica bajo la figura del FEES. En 2010, en el marco de una nueva negociación para el siguiente quinquenio, las universidades públicas se vieron en la necesidad de desarrollar múltiples acciones para garantizar el cumplimiento del FEES por parte del gobierno, incluidas movilizaciones realizadas en distintas localidades del país y una gran marcha en San José a Casa Presidencial el día 15 de junio de ese año. El FEES debería ser un fondo administrado por el Banco Central, pero se ha confundido con una partida más del presupuesto ordinario anual de la República y se le ha reducido a eso. La aprobación del presupuesto universitario tampoco debería estar bajo la competencia de la Contraloría, ya que es suficiente con la aprobación por parte del Consejo Universitario.

La rendición de cuentas por parte de la universidad pública, en razón de las facultades que a esta institución le confiere la autonomía universitaria estipulada en el artículo 84 de la Constitución Política de Costa Rica, no puede estar subordinada a las estipulaciones que en materia de utilización de los presupuestos recibidos por parte del Estado, la legislación nacional establece para el resto y cualquiera otra de las instituciones del país.

En tanto institución de cultura superior, los servicios y "productos" que la universidad pública desarrolla tienen una naturaleza esencialmente cualitativa, cuyo valor para el país y 
para la sociedad no se puede reducir a una estimación econométrica en términos de "valor de cambio". No está de más decir que obviamente tampoco significa que la universidad no deba elaborar sus planes de desarrollo y de operación anual, así como explicar a quien legítimamente corresponda, en qué está invirtiendo las asignaciones presupuestarias que recibe del Estado, lo mismo que aquellas que obtiene a través de otras fuentes de financiamiento.

Inversión en educación superior pública y diversificación de las fuentes de financiamiento

En 2005, en seguimiento a las recomendaciones y resoluciones aprobadas por la CMES 1998 de la UNESCO, la Global University Network for Innovation ${ }^{3}$ (GUNI) convocó a una conferencia mundial con la finalidad de analizar y proponer estrategias y esquemas alternativos para el financiamiento de la educación superior universitaria. En este marco, se estableció una diferenciación respecto de las funciones que les corresponde desarrollar a las universidades públicas y a las universidades privadas.

A las universidades públicas se les definió en la mencionada conferencia de la GUNI como las instituciones "responsables de suministrar el personal del más alto nivel, satisfacer las necesidades sociales de educación superior, garantizar la igualdad en la distribución de la educación superior y garantizar una gestión efectiva" (García, 2008, p. 371). Estas atribuciones definen una diferencia entre las universidades públicas y las privadas. Estas últimas, en general, tienen por finalidad "dar servicio a los intereses privados de los estudiantes" (García, 2008, p. 371).

Las atribuciones que la GUNI señala para la universidad pública, según se puede apreciar, atañen básicamente a la función de la formación profesional. Es decir, no incluye las otras funciones de la investigación y de la acción social. No se va a decir nada aquí al respecto, salvo que quedaría abierta una amplia interrogante: ¿financiamiento para proporcionar formación profesional al más alto nivel y para que se garantice la igualdad en el acceso a los estudios universitarios? Sin duda alguna, esta es una finalidad muy importante

\footnotetext{
${ }^{3}$ Red creada en 1999 por la UNESCO, la Universidad de las Naciones Unidas (UNU) y la Universidad Politécnica de Cataluña (UPC), con la misión de "contribuir con el fortalecimiento del papel de la educación superior en la sociedad, a través de la renovación y la innovación de la enseñanza superior (...) bajo una perspectiva de servicio público, la pertinencia y la responsabilidad social." Véase: Global University Network for Innovation, http://www.guni-rmies.net/info/default.php?id=l.
} 
y de alto valor para la sociedad. No obstante, así planteada, esta orientación vendría a esbozar una visión aún bastante discreta acerca de la universidad pública, cuyas funciones son más complejas y cuyo quehacer académico no se reduce a la docencia ni a la tarea de la formación profesional.

Invertir en educación es una cuestión de importancia estratégica para cualquier país y sociedad. La educación no es una llave que por sí misma pueda ser capaz de abrir las vías del bienestar y contribuir con el desarrollo económico y humano, pero sí es fundamental para el logro de dichas finalidades. También es muy reconocida la importancia de la educación para dar soporte a la movilidad social, así como para que en la sociedad haya igualdad de oportunidades, equidad, justicia social, inclusión, un sistema institucional basado en los principios y la legalidad de la democracia, de respeto a la dignidad humana y que favorezca la autonomía de las personas para que puedan crecer en libertad y desarrollarse personal, social y culturalmente.

La universidad pública tiene en la sociedad una misión y unas funciones cuyo cumplimiento no se puede soslayar desde ningún punto de vista, ni en ninguna de sus dimensiones. La educación superior privada tiene sus límites bien definidos, a partir de que se trata de una inversión cuyo eje está definido básicamente por la oferta de titulaciones y, en una buena proporción de los casos, se trata de una inversión con fines de lucro. Lógicamente, lo que mejor facilita el lucro es la oferta de titulaciones en carreras cortas y de formación técnica. Son muy pocas las universidades privadas que realizan investigación y son aún menos las que desarrollan acción o extensión social.

También, en los últimos años, algunas universidades privadas se han dedicado a ofrecer titulaciones de posgrado, aprovechando la nueva exigencia de la educación permanente o a lo largo de toda la vida. Aquí es importante mencionar la inversión extranjera, que en Costa Rica ya ha conducido a la venta de algunas de las universidades privadas que ofrecen ese tipo de titulaciones. (Umaña, 2008).

Las funciones sustantivas que la universidad desarrolla en la sociedad, en su calidad de institución de cultura superior, pasan a quedar en condición de alto riesgo cuando se obliga a la institución a realizar sus actividades en un escenario y bajo una dinámica de privatización y de lucro. No se trata obviamente de negar la participación de la inversión privada en la educación superior, ni tampoco de decir que no pueda haber una oferta de formación universitaria privada de calidad. 
Pero más allá de la formación profesional universitaria y de una formación profesional de calidad, un país y una sociedad necesitan generar conocimiento y producción de tecnología, que contribuyan con el desarrollo nacional y que a la vez estén a disposición para atender las necesidades sociales (El Universal, 2011), sin mediar fines de lucro. Si fuera lo contrario, entonces la universidad pública vería desnaturalizadas su misión y sus funciones. Dejaría de ser la institución insigne que tiene una muy importante tarea que cumplir, en el marco de la construcción y sustentación de una sociedad basada en la institucionalidad de la democracia.

Conocemos nuestro potencial y las oportunidades que se generan en el intercambio de saberes entre la Universidad y la sociedad. Percibimos los cambios que se han producido y, sobre todo, sus consecuencias en los grupos con mayor vulnerabilidad y eso nos lleva a reflexionar, buscar distintas opciones que no lesionen la soberanía, que no quiebren las garantías y los derechos que con tanto esfuerzo se han logrado, que no irrespeten nuestra historia y nuestra idiosincrasia. (González, 2009, p. 11)

Ante la relación desfavorable que se establece entre las disposiciones de la política pública en materia de facilitar los presupuestos y las necesidades por atender, la universidad pública, en su lugar, ha asumido en Costa Rica la iniciativa de desarrollar por su propia cuenta acciones encaminadas a diversificar las fuentes de financiación. Estas acciones se realizan en el marco de un sistema de educación superior universitaria ampliamente privatizado y en el cual cada día emergen nuevas demandas y necesidades de crecimiento y de desarrollo institucional. En la actualidad, se indica incluso que, en un ejercicio con responsabilidad social de la autonomía universitaria, la universidad pública lleve a cabo esas acciones de manera tal que sirvan para descargar al Estado de algunas obligaciones y responsabilidades (López, 2008, p. 50).

No obstante, estas acciones han sido impulsadas por la universidad pública, haciendo énfasis en que desde ningún punto de vista, sus esfuerzos pueden ser en absoluto considerados como sustitutivos de las responsabilidades y obligaciones que el Estado tiene de garantizar el financiamiento para la educación universitaria estatal. "La venta de bienes y servicios es una opción para las universidades, siempre y cuando se tenga claro que se trata de la obtención de recursos complementarios" (González, 2006, p. 112). 
Asimismo, la universidad pública también impulsa acciones de colaboración interinstitucional, a escala nacional e internacional, dirigidas a establecer condiciones y abrir espacios para el desarrollo de relaciones de cooperación con otras universidades y con diversas instituciones. A escala nacional, se crean fondos de uso compartido entre las universidades estatales, para la investigación, la acción social y la docencia. Se busca además favorecer y democratizar más el acceso a la universidad, por medio del fortalecimiento de la regionalización universitaria: la apertura de nuevos recintos y la ampliación de la oferta académica de grado y posgrado.

A escala internacional, la universidad fortalece sus capacidades de gestión, en busca de establecer lazos con otras universidades de la región y del mundo, desde una perspectiva de cooperación interinstitucional solidaria y de beneficio recíproco. Frente a las tendencias de transnacionalización de la educación superior que hoy recorren el mundo, la universidad impulsa una política y desarrolla acciones de internacionalización, que permitan también atender diversas necesidades de fortalecimiento académico, así como, de manera especial, favorecer la movilidad académica y estudiantil, en condiciones más favorables y a costos más bajos.

No obstante, tal como se ha subrayado, si bien la universidad pública, en efecto, flexibiliza y mejora sus capacidades de gestión para diversificar las fuentes de financiamiento y atender las distintas necesidades de crecimiento que los tiempos actuales le marcan, eso no significa que se deba soslayar la obligación que tiene el Estado de cumplir con el mandato constitucional de otorgar el financiamiento que la universidad pública requiere, a fin de que ésta, a su vez, pueda también cumplir con las responsabilidades que, en tanto institución de cultura superior, tiene con la sociedad y con el país; para que la universidad pueda mantener en pie su propósito de "contribuir con las transformaciones que la sociedad necesita para el logro del bien común." (Universidad de Costa Rica, Consejo Universitario, 2011, p. 1).

\section{Consideraciones finales}

A partir de la década de 1980 y en el marco de la reforma del Estado a que condujeron las políticas de los Planes de Ajuste Estructural (PAE), en diversos países de América Latina variaron el enfoque y la organización del financiamiento estatal para la educación superior pública. El caso más paradigmático de tales variaciones lo constituye seguramente Chile, 
donde a fines de la dictadura de A. Pinochet se instituyó el primer modelo de mercado de la educación superior en un país de América Latina. Este modelo pasaría a ser valorado por el BM como ejemplar, colocándolo como parámetro de las orientaciones que las políticas públicas sobre educación superior deberían adoptar en todos los demás países de la región.

En Costa Rica, la aplicación de las políticas de los PAE representó sensibles restricciones en la dotación de recursos presupuestarios estatales para las universidades públicas. Esta situación condujo a que las comunidades universitarias tuvieran que movilizarse en varias ocasiones para exigir al gobierno la entrega de los presupuestos y que se hicieran cumplir las estipulaciones del artículo 85 de la Constitución Política.

Los resultados de dichas movilizaciones no llegaron a ser del todo fructíferos. Los recortes se impusieron en las universidades públicas y sus repercusiones fueron adversas: estancamiento en desarrollo de infraestructura y equipos; caída de la capacidad adquisitiva real de los salarios universitarios, con la consecuente devaluación de la profesión académica; éxodo de talentos hacia otros espacios laborales; contracción de los programas de becas y de los servicios que se brindan a la población estudiantil, entre otras...

A partir de la firma del primer convenio FEES en 1988, la negociación de los presupuestos estatales para la educación superior pública ha sido con frecuencia complicada, en un contexto en el que las autoridades de gobierno presionan a las universidades para que racionalicen cada vez más el gasto. Esto significa, por ejemplo, reducir la cantidad de las giras estudiantiles que las carreras llevan a cabo a lo largo del año.

En este contexto, es importante tener en cuenta el papel de las políticas públicas para la privatización de la educación superior. A este respecto, cabría decir que la oferta privada de titulaciones universitarias ha propiciado que se cuestione el costo de la formación en una universidad pública, lo que ha conllevado que las autoridades de gobierno promuevan e instituyan una lógica y una esquemática de rendición de cuentas basada de manera privilegiada en indicadores econométricos.

A tal efecto, también es importante subrayar la repercusión que tienen para la universidad pública las nuevas funciones que en el marco de la reforma del Estado costarricense se le han venido otorgando en los últimos años a la Contraloría General de la República (CGR). Como se señaló en el texto, se trata de un proceso de "recentralización" de las instituciones del Estado, en cuyo marco quedan reconfiguradas las autonomías institucionales y sus relaciones con las instancias centrales del gobierno. Para la universidad 
pública, eso ha derivado en una mayor acción intervencionista de parte de la CGR en los procesos de la administración universitaria.

La UCR, en tanto universidad pública y en razón de cumplir con la responsabilidad social que como tal tiene, ha buscado y definido estrategias y mecanismos que le permitan atender las necesidades de crecimiento y de mejora institucional, en todas las dimensiones de su quehacer. Esta es una institución consciente de que debe brindar a la sociedad los servicios que ésta le demanda, en las más óptimas condiciones de calidad y de pertinencia social.

En consonancia con las principales recomendaciones formuladas por la UNESCO en los últimos años, desde hace más de una década, la Universidad ha venido desarrollando una gestión constante, orientada a obtener recursos adicionales provenientes de fuentes alternativas de financiación. Los requerimientos de crecimiento de la institución son diversos y constantes, razón por la cual la Universidad ha desarrollado sus propias estrategias de financiación alternativa. No obstante, tal como lo destaca la Dra. Yamileth González García, esos recursos nunca pueden ser vistos como una sustitución de los presupuestos que el Estado está, por disposición constitucional, obligado a entregar a las universidades públicas.

En general, los enfoques sobre el financiamiento estatal para la educación superior pública, como se indicó en este ensayo, han buscado durante al menos las últimas dos décadas establecer nuevos modelos, con una tendencia a que la universidad diversifique las fuentes de financiación, en razón, según se dice de manera reiterada, de que el Estado ya no está en capacidad de sostener una obligación presupuestaria que se vuelve cada vez más una carga creciente para el erario público. No obstante, también ha habido una tendencia, que tiene su más preferente referencialidad en el modelo chileno del autofinanciamiento, a que la dotación presupuestaria de que provee el Estado, se entregue ya no únicamente a las universidades públicas, sino también a las entidades privadas. Esta orientación implica, por supuesto, un cambio sustancial en el modelo que colocaría a la universidad pública en la inadmisible situación de tener que competir por los presupuestos.

En Costa Rica, tras la aprobación del primer convenio FEES, las universidades públicas, en medio de una constante situación de negociaciones complicadas, han logrado hacer valer los alcances normativos e institucionales que se estipulan en los artículos 84 y 85 de la Constitución Política de la República. Se ha hecho un gran esfuerzo por preservar la validez de la autonomía universitaria, a lo que también se agrega la defensa y validación de 
un modelo de financiación estatal que asegura la prevalencia de la institucionalidad de la universidad pública. Todo esto ha sido resultado de grandes esfuerzos de las autoridades y las comunidades universitarias, así como de la claridad de ambas respecto de lo que significa la universidad pública y de lo que esta institución representa para la sociedad, para la equidad, la inclusión y la justicia social, así como para un desarrollo nacional basado en los principios de la institucionalidad democrática.

La universidad pública, con base en las tendencias y realidades estructurales que definen las políticas públicas de privatización y de transformación de la educación superior desde una perspectiva de mercado, hoy se enfrenta a la necesidad de realizar un análisis urgente y a profundidad, acerca de lo que ella significa como institución de educación superior, con base en las estipulaciones constitucionales que le otorgan el rango de ser una institución de cultura superior.

En tal contexto, la universidad pública deberá continuar desarrollando esfuerzos para preservar las condiciones institucionales de la educación superior universitaria en el país, desde la óptica de un servicio público, cuya privatización y mercantilización no debe conducir en ningún momento a exonerar al Estado de las responsabilidades que por disposición constitucional le corresponde cumplir.

\section{Referencias}

Aguayo López, Miguel Ángel. (2007). Reflexiones acerca de la autonomía universitaria. Universidades, Año LVII, Nueva época (33), 11-15. Publicaciones de la UDUAL, Ciudad de México.

Banco Mundial. (2003). Aprendizaje permanente en la economía global del conocimiento. Desafíos para los países en desarrollo. Recuperado de http://siteresources.worldbank.org/EDUCATION/Resources/2782001099079877269/547664-1099079984605/LLL KE Spanish.pdf

Banco Mundial. (2012a). Documento de evaluación inicial del proyecto para un préstamo propuesto de US\$200 millones para la República de Costa Rica para un Proyecto de Mejoramiento de la Educación Superior. Recuperado de ihttp://www.tec.ac.cr/eltec/BancoMundial/CR HE PAD.pdf

Banco Mundial. (2012b). Documento de evaluación inicial del proyecto para un préstamo propuesto de US\$200 millones para la República de Costa Rica para un Proyecto de Mejoramiento de la Educación Superior. Versión borrador. Recuperado de http://www.rectoria.ucr.ac.cr/www/index.php/documentos/banco-mundial 
Banco Mundial, Gobierno de Costa Rica. (2009). Competitividad en Costa Rica. Recuperado http://siteresources.worldbank.org/INTCOSTARICAINSPANISH/Resources/CostaRicaC ompetitiveness.pdf

Baudrit, Luis. (2005). Repensar la autonomía de la Universidad de Costa Rica. San Pedro de Montes de Oca, Costa Rica: SIEDIN/UCR.

Baudrit, Luis. (2009). Autonomía universitaria y control de la hacienda pública. San Pedro de Montes de Oca, Costa Rica: SIEDIN/UCR.

Castro Montero, Silvia. ( $1^{\circ}$ de junio, 2009). Más allá de lo público y lo privado. La Nación. Recuperado de: http://wvw.nacion.com/ln ee/2009/junio/01/opinion1981922.html

Castro Montero, Silvia. (1 de julio, 2010). No pido que me crean. La Nación. Recuperado de http://wfnode01.nacion.com/2010-07-01/Opinion/Foro/Opinion2430397.aspx?Page=2

Castro Montero, Silvia. (2012). Presupuestos y Autonomía Universitaria. Recuperado de http://silviapcastro.blogspot.com/2012/04/presupuestos-y-autonomia-universitaria.html

Comisión Económica para América Latina y El Caribe - CEPAL. (2000). Equidad, desarrollo y ciudadanía (Versión definitiva). Recuperado de http://www.cepal.cl/publicaciones/SecretariaEjecutiva/1/lcg2071/lcg2071.pdf

CONARE. (2011). Plan Nacional de la Educación Superior Universitaria Estatal 2011-2015. San José de Costa Rica: CONARE. Recuperado de http://www.google.co.cr/url?sa=t\&rct=j\&q=\&esrc=s\&source=web\&cd=1\&sqi=2\&ved=0C C4QFjAA\&url=http\%3A\%2F\%2Faccionsocial.ucr.ac.cr\%2Fc\%2Fdocument library\%2F get file\%3Fp | id\%3D33824\%26folderld\%3D307277\%26name\%3DDLFE13406.pdf\&ei=ad0PUbHpGOfZ2QWh-ID4DA\&usg=AFQjCNGLRtvG icWuHAPejXa7ALkBJ5g\&sig2=u4-Rn-6G7m42hW4HjDdC6A\&bvm=bv.41867550,d.b2U

Conferencia Mundial sobre la Educación Superior - CMES. (1998). La educación superior en el siglo XXI. Visión y acción. Informe final. París: División de la Enseñanza Superior de la UNESCO.

Conferencia Regional de Educación Superior en América Latina y el Caribe - CRES. (2008). Declaración. Recuperado de http://www.udual.org/CIDU/Gacetas/08/87JulDic.pdf

Córdoba Morales, Javier. (26 de junio, 2011). Informe Anual de la Rectora UCR: "Negociación del FEES fue el reto más importante del 2010". Semanario Universidad, (1904). Recuperado el de http://www.semanariouniversidad.ucr.cr/component/content/article/1248Universitarias/4043-informe-anual-de-la-rectora-ucr-negociacion-del-fees-fue-el-retomas-importante-del-2010.html

De la Fuente, Juan Ramón. (2007). Globalización y educación superior. Revista Universidades, Año LVII, Nueva época (34), 3-6. 
Dias, Marco Antonio. (2008). La internacionalización y la cooperación interuniversitaria en la sociedad del conocimiento. En Carlos Tünnermann Bernheim (ed.), La educación superior en América Latina y el Caribe: diez años después de la Conferencia Mundial de 1998 (pp. 313-366). Cali, Colombia: IESALC/UNESCO/Pontificia Universidad Javeriana.

Dias Sobrino, José. (2008). Cambios y reformas en la educación superior. En Carlos Tünnermann Bernheim (ed.), La educación superior en América Latina y el Caribe: diez años después de la Conferencia Mundial de 1998 (pp. 95-140). Cali, Colombia: IESALC/UNESCO/Pontificia Universidad Javeriana.

Didriksson, Axel. (2007). La universidad pública latinoamericana desde su autonomía. Universidades, Año LVII, Nueva época (33), 17-23.

El Universal. (16 de agosto, 2007). Financiamiento, reto para los universitarios: Narro. Recuperado de http://www.elsiglodetorreon.com.mx/noticia/312252.financiamiento-retopara-los-universitarios-n.html.

Frondizi, Risieri. (1971). La universidad en un mundo de tensiones. Misión de las universidades en América Latina. Buenos Aires: Paidós.

Galdames, Luis. (1935). La universidad autónoma. San José, Costa Rica: Editorial Borrasé.

García Guadilla, Carmen. (2008). Dinámicas del financiamiento de la educación superior en el contexto de la diversidad latinoamericana, a diez años de la CMES. En Carlos Tünnermann Bernheim (ed.), La educación superior en América Latina y el Caribe: diez años después de la Conferencia Mundial de 1998 (pp. 367-398). Cali, Colombia: IESALC/UNESCO/Pontificia Universidad Javeriana.

González García, Yamileth. (2006). Educación y universidad. San José, Costa Rica: Editorial UCR.

González García, Yamileth. (2009). V informe anual de labores 2008/2009. San José, Costa Rica: Rectoría de la Universidad de Costa Rica.

Grupo Especial sobre Educación Superior y Sociedad. (2000). La educación superior en los países en desarrollo: peligros $y$ promesas. Recuperado de http://www.tfhe.net/report/downloads/report/bm.pdf

Gutiérrez, Enrique. (2011). Desafía Piñera a estudiantes chilenos y firma unilateralmente la ley de educación. La Jornada. Recuperado de http://www.jornada.unam.mx/2011/08/12/mundo/034n1mun.

Hoy en el Campus, Universidad Nacional. (2010). CONARE pide pronta intervención de Presidenta Chinchilla. Recuperado de http://www.hoyenelcampus.una.ac.cr//index.php?option=com content\&task=view\&id=5 $19 \&$ Itemid $=40$ 
López Segrera, Francisco. (2008). Impacto del Marco de Acción Prioritaria para el cambio y desarrollo de la educación superior. En Carlos Tünnermann Bernheim (ed.), La educación superior en América Latina y el Caribe: diez años después de la Conferencia Mundial de 1998 (pp. 95-140). Cali, Colombia: IESALC/UNESCO/Pontificia Universidad Javeriana.

Masís, José Andrés. (24 de abril, 2012). Conversatorio "Negociación del presupuesto y Autonomía Universitaria", Universidad Estatal a Distancia. Recuperado de http://www.ondauned.com/transmision.php?ou=165

Neave, Guy. (1998). Autonomía, responsabilidad social y libertad académica: debate temático. París: UNESCO.

O'Donnell, Santiago. (2011). Nada es gratis. Página 12. Recuperado de http://www.pagina12.com.ar/diario/elmundo/4-174443-2011-08-14.html

Programa Estado de la Nación. (2011). Tercer Informe Estado de la Educación. Recuperado de http://www.estadonacion.or.cr/estado-educacion/educacion-por-capitulo/educacioninforme-ultimo

Ribeiro Durham, Eunice. (2002). Introducción. En Rollin Kent (comp.), Los temas críticos de la educación superior en América Latina en los años noventa. Estudios comparativos (pp. 9-30). Ciudad de México: Facultad Latinoamericana de Ciencias Sociales/Universidad Autónoma de Aguascalientes/Fondo de Cultura Económica.

Solano Muñoz, Édgar. (2010). La crisis contemporánea de la financiación de la educación superior pública en Costa Rica: un eslabón más de la estrategia neoliberal. Revista Actualidades Investigativas en Educación, 10(Especial), San José, Costa Rica: Instituto de Investigación en Educación. Recuperado de http://revista.inie.ucr.ac.cr/buscararticulos/controlador/Article/accion/show/articulo/la-crisis-contemporanea-de-lafinanciacion-de-la-educacion-superior-publica-en-costa-rica-un-eslabon-mas-de-laestrategia-neoliberal.html

Umaña, Johan. (10 de julio, 2008). Grupo norteamericano compró la ULatina. La Nación. Recuperado de: http://wvw.nacion.com/ln ee/2008/julio/10/economia1615165.html

UNESCO. (2005). Hacia las sociedades del conocimiento. París: Ediciones UNESCO. Recuperado $\quad$ de http://www.google.co.cr/url?sa=t\&rct=j\&q=\&esrc=s\&source=web\&cd=1\&ved=0CC4QFi AA\&url=http\%3A\%2F\%2Funesdoc.unesco.org\%2Fimages\%2F0014\%2F001419\%2F14 1908s.pdf\&ei=3h78UJ7oOsXUiwLS9YDADA\&usg=AFQjCNEgrCdYXHo6iJ25KuzrxLmi YR3N5A\&sig2=3pLS2VhEp6XoVnZRvPM79w\&bvm=bv.41248874,d.cGE

Universia. (2011). Educación superior: Presidente Piñera anuncia creación de fondo de $\$ 4.000$ millones de dólares. Recuperado de http://noticias.universia.cl/enportada/noticia/2011/07/06/843427/educacion-superior-presidente-pinera-anunciacreacion-fondo-4-000-millones-dolares.html 
Universidad de Costa Rica, Consejo Universitario. (2011). Estatuto Orgánico de la Universidad de Costa Rica. Recuperado de http://www.cu.ucr.ac.cr/normativ/estatuto organico.pdf

Vallejo Douling, Camila Antonia Amaranta. (2011). Discurso de asunción a la Presidencia de la Federación de Estudiantes de Chile. Recuperado de http://vozentrerriana.blogspot.com/2011/08/camila-vallejo-lider-estudiantil.html 